\title{
Incentives to improve farm management: EMS, supply-chains and civil society
}

\author{
Neil Gunningham* \\ School of Resources, Environment and Society, Australian National University, Australian Capital Territory 0200, Australia
}

Received 30 October 2004; received in revised form 23 April 2005; accepted 1 June 2005

Available online 7 November 2006

\begin{abstract}
This paper focuses on impediments to environmentally sound management practices and how these might be overcome, with an emphasis on the role of environmental management systems, supply chains and civil society. It argues that:

- Farmers are under increased pressure to cut costs and improve production but with little opportunity to increase prices. Commonly short-term economic interest has damaging environmental implications.

- Current government policy, in Australia and in many other jurisdictions, relies heavily on voluntary arrangements, education and information, as the main policy instruments through which to persuade farmers to adopt better environmental farm managemente.g. the recent push to encourage the use of voluntary environmental management systems.

- However, there is good evidence to suggest that these can only make a valuable contribution when combined with a range of other policy instruments, including positive and negative incentives, intervention by third parties and in some cases, an underpinning of regulation.

- Arguably, what is needed is a strategy that builds on the strengths of voluntary environmental management arrangements while compensating for their weaknesses by combining them with other, complementary policy instruments. If so, we must engage with a range of questions that have not so far figured substantially in the policy debate.

- Although the principal focus has been on the role of government in bringing about on-farm change in management practices, supply chain pressure (at least in respect of agricultural chemicals and practices which threaten food safety) and civil society action are also potentially powerful mechanisms for bringing about change. Government can and should play a role in harnessing such forces in the interests of improved environmental on-farm practices.
\end{abstract}

(C) 2006 Elsevier Ltd. All rights reserved.

Keywords: Agriculture; Regulation; Environment; Environmental management system; Civil society; Supply-chain

\section{Introduction}

Australian agriculture is confronting an environmental crisis. Business leaders, farmers, foresters, scientists and policy makers all point to alarming trends in the degradation of rural landscapes, including rising water tables, increasing salinity, land clearing, loss of topsoil, loss of biological diversity and river algal blooms (Allen Consulting 2002, p. 2). This crisis has serious commercial

*Tel.: + 61261251516 ; fax: + 61261251507

E-mail address: neil.gunningham@anu.edu.au. implications, not only in terms of the declining productivity of a deteriorating land base, but also in terms of the marketability of Australia's agricultural produce. Some $80 \%$ of that produce is exported, much of it though the complex supply chain of an increasingly concentrated, vertically integrated and globalised agrifood industry, which is itself becoming increasingly environmentally sensitive. As a result of these developments Australian agriculture now confronts a range of compelling environmental challenges. These external pressures will almost certainly increase in the future, and the agricultural community will have to respond to them, or face some 
very unpalatable consequences, inflicted by local and international markets and by supply chains, consumers, public interest groups, government or all of the above. But what should such a response involve and how can the transition to commercial and environmental sustainability be achieved? This paper focuses on impediments to environmentally sound farm management practices, and on what policy instruments might best be used to overcome them, with an emphasis on the role of environmental management systems, supply chains and civil society.

\section{A paradigm shift in environmental policy}

Traditionally, government intervention into agricultural environmental practice has been informal, based upon the provision of information and persuasion by government authorities whose fundamental role has been not to police agricultural producers, but to assist them to do the right thing. For example, in the early days, regulation of agriculture focused on the promotion and development of the industry, and even when environmental concerns were raised this did little to change the basic model of agricultural support rather than regulatory control.

Recognising the limitations of the traditional approach, there has been what Mech and Young (2001 xii) describe as "a paradigm shift in how natural resource management and environmental protection are being thought about and approached". This involves the search for new management tools and policy instruments that focus on industry's potential to develop its own solutions through the adoption of various voluntary environmental management arrangements (VEMAs) including not just environmental management systems, but also farm management plans and whole farm plans, nutrient management plans, best management practices, and codes of practice. All of these, in one way or another, are directly concerned to influence farm management practices.

VEMAs such as environmental management systems (EMS) aim to enhance environmental management by improving the way environmental impacts are managed, by lifting the firm's level of environmental performance or by seeking to deliver specific environmental outcomes. Some of them at least can also generate credible systems for measuring and communicating their environmental performance to third parties. This latter function is particularly important since markets are increasingly seeking verification of environmental quality claims. Verification systems which require 'chain of custody' or audit trails from paddock to plate will become increasingly necessary as well as rigorous and detailed systems setting targets and measuring environmental effects. Proponents of VEMAs argue that they hold out the promise of satisfying increasingly demanding supply chain pressure, of helping to protect the 'clean green' image of Australian agriculture while at the same time overcoming many of the limitations of the traditional environmental policy instruments and more successfully engaging with the environmental challenge Australian agriculture faces.

But will these various forms of voluntarism alone be sufficient to achieve these goals? We believe not. There is very considerable evidence, from the use of voluntary instruments across a broad range of environmental issues, that only under very limited and relatively unusual circumstances can pure voluntarism deliver satisfactory results. On the other hand, as argued in subsequent sections, voluntarism has very considerable potential to improve environmental and commercial outcomes when integrated into a broader policy mix. In broad terms it will be desirable to design complementary combinations of policy instruments, tailored to particular environmental goals and circumstances, and also to harness resources outside the public sector (including commercial and noncommercial third parties and business itself) in pursuit of environmental goals (Gunningham et al., 1998). Beyond this however, the answers are likely to be context specific.

\section{The limits of voluntarism: assessing voluntary EMSs}

This section examines the potential contribution of environmental management systems, and ISO 14001 in particular, drawing from a developing body of literature that is summarized below. On the positive side, there is evidence that EMSs can potentially provide a powerful management tool, capable of contributing to substantially improved environmental performance. They place responsibility for decision-making on the people with most information about how best to protect the environment (enterprises themselves), giving them flexibility in achieving their goals, and a structure for doing so, enabling them to identify problem areas, reduce operational costs and provide a systematic way of addressing environmental challenges. If effectively implemented, such systems are capable of raising environmental awareness, motivating employees to search for innovative solutions, ensuring regulatory compliance, reducing environmental impact, delivering cost savings, improving operational efficiency and opening up new markets (Tibor and Feldman, 1997).

Of course, much will depend upon the particular EMS that is adopted. The most widely used system is ISO 14001, which provides a consistent, internationally recognized standard. However, ISO 14001 also has some serious shortcomings. Perhaps the most fundamental concern is that ISO 14001 is a process-based standard which does not guarantee environmental performance outcomes. As a minimum, ISO 14001 certified companies must "commit themselves to conformance with applicable laws and regulations" (as distinct from actually complying with existing laws and regulations) but the standard does not itself set specific goals or performance levels. Nor does it specify rates of improvement, or prescribe specific goals, objectives or policies. Another problem relates to environmental audits and the question of whether such an audit (or a verification of the audit) should be conducted by 
independent third party auditors or can appropriately be done "in-house". Issues of auditor integrity will become particularly acute if ISO 14001 begins to effect market access and international trade (Krut and Gleckman, 1998).

There is tentative, but at this stage not conclusive evidence, that "by building internal awareness of environmental issues, firms [that adopt an EMS] can attain very substantial improvements in environmental performance" (Wells and Galbraith, 1998; Kestemont and Ytterhus, 1997). However, the large majority of research relates to the role of EMSs in the industrial sector and relates to their use by corporations. Far less is known about how such systems play out when applied to agriculture.

Even the research on the industrial sector does not suggest that EMSs will be uniformly beneficial, and indeed some enterprises (who see environmental practices as marginal to their strategic and competitive objectives) appear to treat EMSs as tools for external image manipulation rather than for genuine environmental improvement (Coglianese and Nash, 2001). A major European study across a number of countries found no statistically significant relationship between adoption of a formal EMS and improved environmental performance (Science Policy Research Unit, 2001) Crucially, the results of the most comprehensive report to date, based on the US National Database on Environmental Management, while generally positive, "show that motivations matter. Facilities that reported that the prospects for marketing potential, competitive advantage, increased revenues or support of other professionals were important influences on their EMS adoption decisions showed significantly higher aggregate scores for improvement in their environmental performance indicators."(Buffer and the Allen Consulting Group, 2002). Unfortunately, there are many areas within agriculture where such benefits from adopting an EMS are by no means apparent. For example, the Allen Consultancy report on farm forestry concluded that "it is not clear-cut that consumer or regulators in overseas markets (which have arguably driven Australian producer interest in EMS) are as concerned about salinity or land degradation in Australia as they are about, say, chemicalfree food. Until the business case for an EMS linked to specified environmental outcomes is firmly established, widespread uptake by conventional (particularly smaller) producers, will be delayed" (Buffer and the Allen Consulting Group, 2002, emphasis added).

These findings are consistent with a broader, and crucially important theme that emerges from studies of EMS, namely that enterprises are only likely to commit substantial resources to such systems, rather than making tokenistic efforts to comply, where they perceive a strong economic self-interest in doing so, and most commonly they do not. Thus Sullivan concludes from a survey of the role of EMSs that "while environmentally proactive organisations will set challenging targets for themselves and adopt a leadership position, others will adopt a more minimalist approach ... that is, organisations are acting as economic rationalists [and] beyond compliance initiatives will only be taken if there are clear returns ... without broader pressures to move towards the goal of sustainability, this will continue to be the case. That is, EMSs are not the panacea or perfect solution for unsustainable business practices." (Sullivan, 2001, p. 601, emphasis added). It should be added that in many areas of agriculture, EMS adoption is still very low, raising further doubts about the value of voluntarism in this context.

This focus on voluntarism alone is unfortunate, because getting EMS (or codes of practice or other voluntary initiatives) to work is far more complex than the debate in Australia has so far recognised. In the following section it will be demonstrated that there are various means by which governments and interested stakeholders can encourage enterprises to adopt voluntary environmental approaches. The key is to find the right mix of incentives (legal, economic, market based, reputational, etc) for specific national contexts. If we fail to do so, then mechanisms such as EMS, which have the potential to make a very substantial contribution to sustainable agriculture, in practice, may fail to do so.

\section{Beyond voluntarism: towards an optimal policy mix}

We have argued that the best means of overcoming the deficiencies of VEMAs such as EMS while taking advantage of their strengths is through the use of additional and complementary policy instruments. But which particular combination of instruments will be most appropriate? A wide range of instruments might potentially be used to mitigate the adverse environmental impact of various agricultural practices and move those practices closer to sustainability. At a conceptual level, those instruments can be classified under five headings: regulation, economic instruments, education and information strategies, self-regulation and voluntarism. The last two categories are very closely related-voluntarism refers to individual initiatives and self-regulation to collective ones - and most VEMAs fall into one or other of them. For present purposes, the question is: how might VEMAs, and in particular EMSs, effectively be combined with information and education strategies, economic instruments and regulation?.

Threats to the environment take many forms with the result that strategies to address environmental degradation are commonly context-specific with the sorts of policies that work being highly dependent upon the characteristics of the environmental issue under consideration. As a result, it would be futile to attempt to construct a single optimal regulatory solution that would be applicable to a wide variety of circumstances. Nevertheless, it is possible to build a principle-based framework for integrating VEMAs into broader policy mixes in any given circumstances. By this we mean an approach that leads policymakers to assess their decisions against a set of design criteria (principles) that form the basis for reaching preferred policy outcomes. Below we 
seek to develop such an approach, drawing both from the theoretical literature on environmental policy instruments and from our own past and current empirical study of what works and what does not work in specific contexts.

\subsection{Information and education are necessary to underpin VEMAs but rarely sufficient in themselves to achieve preferred environmental outcomes}

A necessary underpinning to any other strategy is the effective provision of information and education. Ignorance of their environmental impact and a lack of skills, and expertise to do something about it, are major obstacles to better environmental performance. Only when enterprises are aware of their environmental impact, know of more environmentally responsible means of behaving, and know of their legal responsibilities, are policy-makers in a position to ask agricultural enterprises to "do the right thing". In its more sophisticated forms, the provision of information and education may also facilitate the acquisition of specialised skills and knowledge, without which improved environmental performance is unlikely to be sustained. Not least, it will be important to raise awareness about the value of EMSs and codes of practice in more sustainable land use as a precursor to encouraging their widespread use.

But even if education and training are well targeted and presented, it is unlikely that they will be enough in themselves to achieve widespread behavioural change because a number of other motivational pressures described above may militate against voluntary action. Information and education work best where targeted enterprises perceive self-interest in adopting the recommended measures (Barr and Cary, 2000). Where this is not the case (as when the desired behaviour is unprofitable) then information and education alone are very unlikely to be dependable policy instruments and for this reason are best used in combination with other instruments. Nevertheless, information and education remain necessary although certainly not sufficient, to achieve the improved environmental performance of light industry.

\subsection{VEMAs must be designed to ensure improved environmental outcomes. This implies performance indicators/outcomes, accountability, transparency and consultation}

VEMAs are unlikely to make a substantial contribution to improved environmental performance unless they are carefully designed. Neither codes of practice nor EMSs are likely to function effectively in the public interest in the absence of adequate mechanisms ensuring accountability and transparency. Where an enterprise self-monitors there will be a temptation to misrepresent the results, providing an overly favourable account of its environmental performance, particularly if there are regulatory or public relations benefits to be gained from so doing. Irrespective of whether firms succumb to this temptation or not, the public will not trust the results. In the case of EMS, experience suggests that identifying environmental targets, performance monitoring, measuring and verification, third party audits and transparency are all vitally important. Failure to satisfy some of these criteria has resulted in substantial criticism of the ISO 14001 standard by NGOs. If enterprises adopting EMS do not voluntarily address these criteria they may well find that the VEMA does not achieve its intended effect and that external markets are unpersuaded by environmental claims made about it.

\subsection{VEMAs can play important roles but only under specified (and rarely satisfied) conditions can they be relied upon as 'stand-alone' policy instruments}

VEMAs such as EMS work better in some circumstances than in others, and not all industries lend themselves to such initiatives through industry associations. A review of the literature relating to voluntary agreements and industry self-regulation suggests that necessary (but as we will see, certainly not sufficient) conditions for the success of such initiatives are either:

(1) a strong natural coincidence between the public and private interest in establishing such agreements or;

(2) the existence of one or more external pressures sufficient to create such a coincidence of interest.

In almost all other circumstances, VEMAs are not a substitute for some form of external incentives or pressure, whether economic or in the form of regulation. Given the reticence of landholders to adopt voluntary measures when they have no immediate self-interest in doing so (as when the costs of establishing an EMS outweighs the perceived benefits) VEMAs should not be used in isolation (or solely in conjunction with education and information strategies) except in those limited circumstances where the public interest in environmental protection and the private interests of landholders substantially coincide. But in other circumstances there is the potential for governments to intervene to achieve better outcomes for the community as a whole. Here, the limitations of VEMAs as stand alone instruments, can often be compensated for, and their strengths, enhanced, by combining them with some other policy instruments. But which ones?

\subsection{Use complementary combinations of policy instruments to compensate for the deficiencies of VEMAs}

Precisely what form of intervention will provide the most appropriate underpinning to VEMAs is likely to vary with the particular circumstances of the case. However, it is at least possible to identify some of the most commonly important variables.

First, given that government resources are already overstretched, there is a compelling need to use them 
efficiently and to identify a means by which it might be possible to either replace or complement government regulation. One important strategy for doing so is to delegate regulatory responsibilities to other parties in circumstances where this is a viable option, thereby freeing up resources which can be redeployed to areas where there is no alternative to government enforcement. For this reason, one should look first to market solutions. Where these do not emerge, governments can seek to stimulate them. Where these efforts are unsuccessful, incentives targeted directly at producers may be required. The question of incentives is further explored in principle 5 below. Second, third parties acting as surrogate regulators, will often be a useful complement to the role of general law (see Boxes 1 and 2). Third it is often crucial that VEMAs operate in the shadow of rules and sanctions provided by the general law, for it is these which are the most obvious and visible (but not the only) means of giving enterprises the incentive to comply with the VEMA.

\subsection{Use economic incentives where practicable, to encourage the use of VEMAs}

Incentives can play important roles in encouraging the adoption of VEMAs. They will be particularly important in doing so, given the lack of immediate self-interest in so doing in many circumstances, and other obstacles to their adoption, identified above. For example relevant incentives might include:

(i) Using government investment under the National Action Plan for Salinity and Water Quality to assist or encourage individual landholders to adopt EMS that lead to appropriate farm management and collectively contribute to regional catchment targets.

(ii) Using EMS as a criterion for allocating publiclyfunded stewardship or conservation payments. For example, EMS adoption could be a pre-requisite for government funding, or used to ensure ecosystem or conservation services provided by landholders.

(iii) Governments implementing preferred supplier schemes that give preference to products supplied by farmers able to demonstrate environmental management or adoption of a specified VEMA.

(iv) Governments providing fiscal incentives (grants, tax concessions or sustainable land use investment companies) to make greater use of EMSs and to facilitate on-farm investment that is required to change farming practices.

(v) The adoption of a 'performance track' or 'fast track' under regulation, which gives preferred treatment and greater flexibility to those who have adopted a specified VEMA.

However, incentives which encourage the adoption of an EMS do not necessarily ensure improved environmental performance, unless the EMS is closely tied to agreed performance indicators and meets the other criteria specified under principle 2 above. There remains a considerable risk of tokenism and of the adoption of 'paper systems' of little value if these criteria are not met (see, for example, Coglianese and Nash, 2001).

The problems are exacerbated by the fact that in some circumstances it will not be practicable to identify measurable performance outcomes (decline in salinity, improvements in downstream water quality, etc). In these circumstances, EMS still have the potential to provide a basis for paying for environmental services, such payment being based on compliance with an EMS in terms of onfarm activities. Such on-farm investments could also be tax-advantaged (Coglianese and Nash, 2001).

Finally, notwithstanding the seeming superiority of market-based instruments (taxes, subsidies and markets) in theory, in providing incentives to land users to minimise abatement cost, barriers to the adoption of such instruments, such as high administration and monitoring costs, may make them much less attractive in practice with the result that "other instruments - such as regulationcannot be ruled out, being more cost effective in some cases." (Productivity Commission, 2003).

\subsection{Use reinforcement and pull-push combinations for optimal results}

Two additional elements of optimal regulatory mixes must be emphasised: the capacity to achieve better results through activation and reinforcement of one instrument by another; and the importance of designing "push-pull" combinations.

Reinforcement: Some instruments enhance or reinforce others. For example, in the abstract, codes of practice are only voluntary measures which are of guidance to members and of no consequence whatsoever to non-members. However, they are important in shaping indirectly the regulatory environment, and in influencing an enterprise's perceptions of it. In Queensland, codes of practice can take on a more formal status, serving (when formally approved) to discharge the 'general environmental duty' as set out in the Environmental Protection Act 1994, Section 36.

Using combinations which both "push and pull": Organisations are commonly complex entities with multiple objectives, and indeed, multiple selves. As a result, strategies which appeal to different motivations, which combine both carrots and sticks and which both pull and push enterprises towards better environmental performance, are likely to be more effective than those which invoke only one of these approaches. For example, we emphasise the importance of providing a series of incentives for enterprises to participate in regulatory flexibility programs incorporating ISO 14001 (or "ISO Plus"). These incentives will function much better if the alternatives to participation are also made far less palatable. For example, if non-participants are sooner considered for intensified enforcement activities relative to 
Box 1

Supply chain pressure and the power of the market

The last several decades have seen widespread change in the economic and social context of agriculture and in rural communities. As agriculture has become increasingly industrialised, the traditionally independent farmer has become more integrated into the market-driven supply chains of the global agrifood industries (e.g., multinational supermarket chains) which now have major influence on all aspects of agriculture-including pest control. Much of this influence has been achieved through the growth of contract farming, particularly in horticultural industries. By contracting with farmers for a specified annual tonnage of produce of an agreed and consistent standard at a set price, food processors, supermarkets and fast food chains can effectively utilise their corporate market power to impose quality requirements on growers whilst minimising their direct exposure to the uncertainties and risks associated with farming.

Crucially, retailers' quality requirements now include guarantees of both the safety of the food products and the environmental impact of their production. This is largely in response to growing consumer demand that their food be guaranteed free from contaminants and chemical residues, as well as meeting a variety of other requirements such as taste, size, colour, freshness and lack of blemishes. This concern with safety is not surprising as globally publicised food scares (such as BSE, foot and mouth disease and the Belgian dioxin scandal) continue to erode consumer confidence in food safety and the capacity of government and industry to maintain adequate standards. Similarly, as the environmental impact of agricultural chemicals becomes more evident, consumer concern about the broader environmental and social impacts of food production methods is also increasing.

In response to this erosion of trust, and attempting to capture greater market share and sometimes premium prices, multinational food retail chains have adopted quality and safety standards that substantially exceed regulatory requirements. As well as the regulatory imposition of residue testing, the major food retailers now require adoption of hazard analysis and critical control point (HACCP) based quality assurance measures that guarantee safe food production along the supply chain. This has a number of advantages for retailers. It publicly demonstrates corporate capacity to safeguard the safety and quality of the food sold and corporate concern about the health, environmental and social implications of its production. Accountability for food safety and quality-and the costs involved-are transferred right along the supply chain to those who grow the food.

In response to growing community pressure for greater corporate social responsibility, some of the larger food retailers are also adopting protocols that emphasise the social impact of food production. For example the EUREPGAP (Euro-Retailer Produce Working Group, Protocol on Good Agricultural Practice) Terms of Reference require the commitment of participating member organisations to; "Respond to Consumer Concerns on Food Safety, Animal Welfare, Environmental Protection and Worker Welfare", This requires adoption of integrated pest and crop management (IPM and ICM) and includes both mandatory and recommended ("encouraged") provisions for comprehensive assessment and management of food safety, environmental and OHS risk along the whole supply chain.

However, as farmers face having to meet the resulting increases in production costs, they may take other risks in order to achieve short-term economic goals. In the case of pest control, the cheapest option to achieve the required pesticide residue levels (MRLs) may not be the one least hazardous. For example, farmers can continue the hazardous use of organophosphate insecticides to control pest infestations on mature vegetable crops and still meet pesticide residue MRLs if they observe the recommended delay in harvesting.

participants, then there is both the push of negative sanctions as well as the pull of positive rewards, to induce enterprises to join.

\subsection{Order the introduction of instruments for optimal effect}

Even assuming that an instrument mix is preferred to single instrument approaches, there may be reasons for ordering the introduction of the various instruments, rather than introducing them at the same time. This point has previously been made by Gunningham and Young (1997). For example, it would seem sensible to remove or neutralise existing perverse economic incentives first, since these would otherwise distort or reduce the effectiveness of new policy instruments. Where a tax concession is inducing unacceptable vegetation clearance then it is more economically efficient to remove the tax concession than to attempt to prohibit clearing. Again, where more than one instrument or combination of instruments might achieve the intended policy outcome, it would also be appropriate to 


\section{Box 2}

Harnessing third parties: pesticides and the power of partnerships

There is considerable potential to harness the energies of NGOs in the interests of improved pesticide safety, through the development of partnerships between NGOs and industry, or even between NGOs, industry and government. This approach is exemplified by "green alliances" established between an agricultural sector or an individual enterprise, and one or more environmental organisations.

Take the case of the wisconsin potato and vegetable growers association (WPVGA), who for health, environment and economic reasons, had been concerned to reduce the use of broad-spectrum, high risk pesticides. It was attracted to the use of IPM not least because of: "its capacity to expand profit margins by avoiding unnecessary pesticide applications and reducing pest pressure through a variety of means, some of which entail little or no cost".

WPVGA did not need a partner to develop IPM but it did need some means of marketing the environmental advantages of low residue Wisconsin potatoes, and help in developing a premium market for environmentally friendly potatoes. Enter the world wildlife fund (WWF), an international and high profile environmental NGO whose panda logo and reputation could potentially provide considerable public relations, marketing and credibility advantages to WPVGA. In particular, the potato growers hoped the partnership with WWF would: (1) document progress in the adoption of bio-intensive IPM and reduction in reliance on high-risk pesticides; (2) quantify public health and environmental gains achieved as a result of industry-wide commitment to IPM; (3) gain recognition for Wisconsin potato products, especially in quality conscious markets; and (4) support policy reform and public and private investments needed to enhance the effectiveness and lower the cost of bio-intensive IPM.

For WWF, the partnership also held considerable attractions. For some time, WWF had been concerned to lessen reliance on pesticides and had identified IPM as the surest way to achieve this objective. Through the project WWF hoped to demonstrate: (1) the value of setting measurable pesticide use, risk, and IPM adoption goals, and ways to do so; (2) how monitoring and rewarding progress toward concrete goals can build the momentum needed to overcome technical and marketplace hurdles; (3) a cooperative model for partnerships involving environmental and commodity groups committed to common goals; and (4) analytical tools and policy innovations that will help achieve national IPM, food safety and environmental quality goals.

While the success of this partnership is by no means clear, it does illustrate how groups that have traditionally adopted adversarial positions, both have much to gain through cooperation, and how this could have considerable spin off benefits for the environment in some contexts. Notwithstanding difficulties that emerged in the partnership arrangement, the early results from the project demonstrated a quite striking level of success: "Wisconsin reduced use of high-risk insecticides by over $60 \%$ in a year when national insecticide toxicity units per acre went up 6\%. Toxicity units associated with all herbicides, insecticides and fungicides applied in Wisconsin fell 20 percent between 1995 and 1997, but rose 16\% nationwide."

Source: Gunningham (2002).

introduce less intrusive and interventionist instruments before more intrusive ones.

A policy instrument is more likely to produce both improved environmental performance and a positive attitude change if it is perceived as non-coercive. This is particularly important in the agriculture sector, given its traditional antipathy to command. It therefore follows that instruments should be no more coercive than circumstances require. To this end, Gunningham and Young (1977) recommend the sequenced mobilisation of instruments in ascending order of coerciveness. Voluntary instruments are likely to be preferred by resource users over direct regulation because they are often more flexible, and they grant individuals greater freedom and opportunities to innovate. By offering a choice, they are likely to be perceived as more legitimate, thus facilitating compliance. There are also more positive reasons for preferring noncoercive responses, (and for decentralising decision-making): specifically, to draw on farmer's expertise and on-theground management skills in searching for ways to combine agriculture with environment protection and tailor pesticide and fertiliser use to local conditions.

\subsection{Where necessary, build in a regulatory underpinning}

In some circumstances, it may not be practicable to provide incentives of the kind described at principle 5 above, or such incentives may not be effective (or, given 
administrative or monitoring costs, cost effective) in addressing the issue at stake. And where dependability is crucial, (as when seeking to prevent irreversible environmental damage) incentives are in any event less reliable than regulation. In the above circumstances, VEMAs should operate in the shadow of rules and sanctions provided by the general law, for it is these which are the most obvious and visible (but not the only) means of giving regulatees the incentive to comply with the self-regulatory program. Even where incentives do play a role, combining instruments may be more effective than single instruments alone.

Certainly, there is considerable evidence from a variety of jurisdictions, that it is largely fear of government regulation that drives the large majority of EMS. For example, evidence from a database of approximately 2000 manufacturing firms in 9 European countries suggests that regulatory factors (and sometimes commercial factors) are crucially important in encouraging firms to undertake EMS. Accordingly, it seems unlikely that they will perform well, in the absence of continuing government oversight and the threat of direct intervention. As Griffin and Alexandra have pointed out: "regulation plays a key role in signaling to commercial operators what is expected in terms of societal responsibilities. EMS can play a useful accompanying role in reporting on how these are being met and in addressing a range of factors that are beyond compliance" (Griffin and Alexandra \& Assoc, 2002).

However, it must be recognised that environmental regulation works best where a single standard can be applied to all duty holders and "where land users and their properties are similar; the 'cause and effect' relationships are well understood; there is a high probability of serious environmental damage; and this damage can clearly be linked to the land use being controlled" (Productivity Commission, 2002). This is not the case with many of the most serious environmental problems confronting Australian agriculture. For example, "the costs and benefits of particular management practices can vary markedly between different properties, depending on factors such as their proximity to a water course, soil type, and topography"(Productivity Commission, 2002). Moreover, prescriptive regulation is ill-suited to controlling some problems because of the limited information held by policy makers as to abatement costs.

Nevertheless, there are a substantial range of circumstances where regulation can and should play an important role. These include prohibiting activities that are unsustainable, such as land clearing in certain circumstances, controlling land and water use, zoning with regard to planning decisions and rules concerning protection of the riparian zone.

Even in circumstances where no single standard can be applied there is still scope for the introduction of a general environmental duty (as is the case in four jurisdictions in Australia). The virtue of this approach, particularly as applied in Queensland under Section 36 of the Environ- mental Protection Act 1994, is that it sets a general standard in broad terms (therefore capable of applying in a wide range of circumstances) which can then be refined and further specified by tying it to an approved code of practice or EMS. For example:

(i) an audited EMS that meets established natural resource management standards may demonstrate a commitment to a duty of care to the land;

(ii) a property vegetation management plan be developed by a landholder as a strategy to plan and maintain remnant vegetation areas on their property (and must accompany an application to clear native vegetation). An approved PVMP in turn could form the vegetation protection component of an EMS;

(iii) an approved Land and Water Management Plan is required by legislation and in turn could form the core material of a property EMS. Conversely, an audited EMS that meets established land and water management practices may be recognised as satisfying some LWMP requirements.

\subsection{Design financially attractive mixes}

Gunningham and Young (1997) have argued that where ongoing and active contributions to sustainable agriculture are required, financially attractive instrument mixes should be preferred to ones that reduce the welfare of producers. This is particularly the case given the "bottom line" focus of most producers, and the cultural heritage of subsidisation which has characterised western agriculture. In Young's view, the overall success of a policy regime will be substantially higher and the prospects for sustainable agriculture will be greater if direct regulatory approaches are overlain with a web of mechanisms that create a financially attractive and voluntary atmosphere encouraging cooperation and the sharing of information (Young et al., 1996). For reasons described below, only the latter approach is likely to induce resource users and communities to actively contribute to sustainable practices.

There are a variety of ways in which financially attractive instrument mixes can be created. For example, in many countries, it has become common to use financial instruments to close the gap between the private and public demands for biodiversity conservation. Often the incentive offered is less than the full cost of an action. For example, in Western Australia, landholders are offered 50 per cent of the cost of fencing out remnant native vegetation and, if they sign a 30-year memorandum of understanding to maintain that remnant, a significant local government rate rebate will apply. Also in Western Australia, sharefarming arrangements have been developed whereby farmers receive an annuity for allowing the state or private forestry companies to grow and harvest timber on their land. Sustainable management of such timber resources will help conserve biodiversity and arrest soil degradation. 
In the domain of agricultural chemicals, incentives for moving from traditional methods to low-input production would be an attractive alternative, or at least complement, to a levy imposed on inputs. Cross-compliance, where eligibility for a benefit is conditional upon compliance with regulatory requirements, is preferable to simple direction.

Financially-attractive mixes are particularly important where there is a need to encourage ongoing management of a resource: a situation where negative regulation is likely to be particularly ineffective. Policy instruments which merely halt existing damage to natural resources are important, particularly in gaining breathing space during which more constructive policies can be developed, but they do not in themselves ensure that resources will be appropriately managed so as to preserve the environment. The final element in terms of ensuring ongoing management of resources is some mechanism (e.g., a covenant or easement) to ensure that protection does not cease with the termination of the management agreement.

\section{Conclusion}

EMSs can play important roles in moving Australian agriculture towards sustainability and improving natural resource management. They have the capacity to encourage the management of environmental impacts on a methodical basis, to enhance environmental performance, facilitate continuous improvement and initiate cultural change. However, they are unlikely to realize their potential if they are used as 'stand alone' instruments of environmental policy. As has been argued above, there are insufficient incentives for most landholders to adopt such instruments (as is borne out by the very low rates of adoption in many agricultural industry sectors). Current government policy, to the extent that it is limited to providing information and education about such approaches, will be largely ineffective where the desired behavioural change is unprofitable. Moreover, even when landholders are persuaded to adopt such instruments, they often have insufficient incentive to put in the hard yards to make them work. Lacking commitment, what commonly results is paper systems and tokenism.

However, EMSs could play an important role in enhancing risk management and building in continuous improvement, if they are used in combination with a number of other policy instruments. Where they include appropriate performance indicators/outcomes, accountability, transparency and consultation, where there are credible incentives to encourage their use and/or an effective regulatory underpinning, and where third parties are harnessed to contribute to policy goals, then they can not only lead to improved environmental performance but also, given their greater credibility in these circumstances, serve to protect agri-industry from international pressure for environmentally sustainable/ healthy produce.

\section{References}

Allen Consulting, 2002. Environmental and Commercial Outcomes Through Agroforestry/Canberra. RIRDC.

Barr, N., Cary, J., 2000. Influencing Improved Natural Resource Management on Farms: A Guide to Understanding Factors Influencing the Adoption of Sustainable Resource Practices. Social Sciences Centre, Bureau of Resource Sciences, Canberra.

Coglianese, C., Nash, J., (Eds) 2001. Regulating from the Inside: Can Environmental Management Systems Achieve Policy Goals. Resources for the Future, Washington, DC.

Griffin and Alexandra \& Assoc, 2002. The ECOVINE Project. Land and Water Australia, Southcorp and Australian Conservation Foundation.

Gunningham, N., 2002. Green alliances: conflict and cooperation in environmental policy Australian. Journal of Environmental Management 9 (4), 2-51.

Gunningham, N., Young, M., 1997. Towards optimal environmental policy: the case of biodiversity conservation. Ecology Law Quarterly 24 (2), 243-298.

Gunningham, N., Grabosky, P., Sinclair, D., 1998. Smart Regulation: Designing Environmental Policy. Oxford University Press, New York.

Kestemont, M.P., Ytterhus, B., (Eds) 1997. European Business Environmental Barometer Report prepared for EC DGIII, Research Report [SUB/97/5005441/UCL]. Brussels; European Commission.

Krut, R., Gleckman, H., 1998. ISO 14001: A Missed Opportunity for Sustainable Global Industrial Development. Earthscan Publications, London.

Mech, T., Young, M., 2001. Voluntary Environmental Management Arrangements. RIRDC, Canberra.

Productivity Commission, 2003. Industries, Land Use and Water Quality in the Great Barrier Reef. Melbourne.

Productivity Commission, 2002. Industries, Land Use and Water Quality in the Great Barrier Reef (Draft Report). Melbourne.

Sullivan, R., 2001. Environmental management systems: theory, Practice and implications for law and policy. Environmental Planning and Law Journal 18 (6).

Tibor, T., Feldman, I., 1997. Implementing ISO 14000: A Practical, Comprehensive Guide to the ISO 14000 Environmental Management Standards. McGraw-Hill, USA.

Wells and Galbraith, 1998. The Firm, The Environment and Public Policy. OECD, 2001 env/EPOC/WPNEP (2001) 31/final.

Young, M.D., et al., 1996. Reimbursing the Future: an evaluation of motivational, voluntary, price-based, property-right, and regulatory incentives for the conservation of biodiversity. Biodiversity Series Paper No 9. Canberra; Biodiversity Unit, Department of the Environment, Sport and Territories. 